\title{
Hypertension and Its Socioeconomic Factors in a Market Population in Awka, Nigeria
}

\author{
Ernest Ndukaife Anyabolu ${ }^{1,2, *}$, Innocent Chukwuemeka Okoye ${ }^{1}$, Anuli Nkechinyere Chukwumobi ${ }^{1,2}$, \\ Onyebuchukwu Desmond Eke ${ }^{1,3}$ \\ ${ }^{1}$ Department of Internal Medicine, Chukwuemeka Odumegwu Ojukwu University Teaching Hospital, Awka, Nigeria \\ ${ }^{2}$ Department of Internal Medicine, Imo State University Teaching Hospital, Orlu, Nigeria \\ ${ }^{3}$ Department of Pharmacology, Nnamdi Azikiwe University, Nnewi, Nigeria \\ *Corresponding author: enhealer@yahoo.com
}

\begin{abstract}
Background and Objectives: Hypertension is a major healthcare problem in Nigeria with a probable prevalence of $36.6 \%$. A large population of Nigerians are engaged in market activities. This study was set out to determine the prevalence of hypertension and the factors which may influence it in a population of market workers in Awka, Southeast Nigeria. Methodology: This was a cross-sectional study conducted in an unstructured market workers' population. The subjects were screened for hypertension and its potential associated factors. The results were compared between the hypertensive and the non-hypertensive groups. Results: The prevalence of hypertension was $41.5 \%$. The prevalence of unawareness of hypertension was $54.1 \%$ among those who were hypertensive. Increasing age, non-smoking, poor educational status, thickened arterial wall, marriage, diabetes mellitus, low economic status, small number of persons living in an apartment, fair complexion as well as positive family history of hypertension were significantly associated with hypertension. Thickened arterial wall and tobacco snuff use predicted hypertension. Conclusion: The prevalence of hypertension and unawareness of hypertension were high in this study. Obesity, cardiovascular risks, small family size, low income and low educational status were common among hypertensive subjects in the market population.
\end{abstract}

Keywords: hypertension, prevalence, thickened arterial wall, BMI, low economic status, marital status, low educational status, family size, Awka, Nigeria

Cite This Article: Ernest Ndukaife Anyabolu, Innocent Chukwuemeka Okoye, Anuli Nkechinyere Chukwumobi, and Onyebuchukwu Desmond Eke, "Hypertension and Its Socioeconomic Factors in a Market Population in Awka, Nigeria.” American Journal of Medical Sciences and Medicine, vol. 5, no. 3 (2017): 40-48. doi: 10.12691/ajmsm-5-3-1.

\section{Introduction}

Hypertension is a global healthcare problem in both the developed and the developing countries. [1,2,3] The world prevalence of hypertension was put at 26.4\%\% [2]. Variable prevalence rates have been observed in different parts of the world, with Poland 68.9\% [2], China 9.1\%\% [4] and USA 29.1\% [5]. In Sub-Saharan African countries, the prevalence is not completely known. Kenya reported 22.8\% [6], Cameroon 16.4 - 29.4\% [7] and Ghana 19.3 54.6\%. [8] However, a recent study reported a prevalence of $36.6 \%$ in urban areas and $26.4 \%$ in rural areas in Nigeria. [9] Different Nigerian studies have shown that the prevalence rates of hypertension in Nigeria range from $26.4 \%$ to $36.6 \%$. [9]

It has been demonstrated that many individuals who have hypertension were unaware of their condition. $[5,6,10]$ A study in Enugu, Nigeria, showed unawareness prevalence of $70.6 \%$ among those who have hypertension [10].

Hypertension is a cardiovascular risk problem [11] and has been associated with high morbidity and mortality. [12]
It puts a lot of stress on the economy of both the developed and the developing countries. [13] Around the world, the incidence of hypertension has been projected to be rising. [14]

Some associated factors of hypertension have been identified. They include age, consumption of red meat, body mass index (BMI), and the number of children in the family. [10,15] If uncontrolled, hypertension may lead to cardiovascular end-points which include blindness, renal damage, heart failure, stroke, dementing illnesses, ischemic heart disease among others. [16,17,18]

There is a paucity of studies on the prevalence and risk factors of hypertension in Nigeria. It is on the strength of this that we embarked on this study to determine the prevalence of hypertension and the factors which may influence it in a market workers population in Awka, Nigeria.

\section{Materials and Method}

The study population consisted of 294 subjects drawn from Eke Awka Main Market, made up of mainly artisans, traders, hawkers, among others. The management of the 
market gave approval and cooperation for this study. Through this management leadership, announcement through a gong crier was made, informing the participants of the study. Informed verbal consent was obtained from each of the participants. The objectives and aims of the study were explained to them. Data were collected using a questionnaire which was pretested on those hypertensive and those non-hypertensive. Addressed in the questionnaire were biodata, family history of hypertension, diabetes mellitus status, cigarette smoking, tobacco snuff use, educational status, alcohol use, marital status, eating at home, meat consumption, night-time sleep duration, keeping night vigil, prior knowledge of hypertension status, economic status, days spent on business in a week, days spent on weekend, annual leave duration, number of persons living in same apartment, number of dependants, social activities, siesta, keeping GSM phones on during night sleep, making mid-night GSM phone calls, finding time to rest in the evening, using Akanwu, complexion, length of time spent at work daily.

Demographic and anthropometric data were collected. Weight (kg) and height (m) were taken and BMI was determined as weight $/$ height ${ }^{2}\left(\mathrm{~kg} / \mathrm{m}^{2}\right)$. Radial and brachial arteries were examined for thickening, and pulse rate was obtained. Blood pressure ( $\mathrm{mmHg}$ ) was recorded from the non-dominant hand in sitting position, after the subjects had rested for 10 minutes, using appropriate cuff size to cover about $80 \%$ of the arm, and Accoson mercury sphygmomanometer. Three blood pressure readings were taken 5 minutes apart, and the average obtained. [10]

The variables were graded into groups as follows:

Smoking: 1) those who were smokers and 2) those who were non-smokers

Tobacco snuff use: 1) those who used tobacco snuff and 2) those who did not

Alcohol: 1) those who have positive alcohol history and 2) those who have not

Educational status: 1) no formal education, 2) primary, 3) secondary, 4) tertiary

Arterial wall: 1) those who have thickened arterial wall and 2) those with normal arterial wall

Marital status: 1) single, 2) married, 3) divorced, 4) widowed Eating at home: 1) those eating at home and 2) those eating outside the home

Meat consumption: 1) those who consumed a lot of meat and 2) those who did not

Night-time sleep duration: A) >6 hours, B) $4-6$ hours, C) $<4$ hours

Night vigil: 1) keeping night vigil and 2) no night vigil

Diabetes mellitus: 1) those known to be diabetic prior to the screening and 2) those whose diabetic status was not known prior to the study

Hypertension: 1) those that knew they were hypertensive prior to the study and 2) those whose hypertensive status was not known prior to the study

Economic status: 1) Artisan, 2) minor retailer, 3) major retailer/importer, 4) hawkers, 5) clerical staff, 6) banker, 7) government worker, 8) transport worker, 9) collectors, 10) others

Week days spent in business: A) 1 - 3 days, B) $4-5$ days, C) 6 days, D) 7 days

Number of days spent on weekend: A) 1 day, B) 2 days, C) 3 days, D) none
Annual leave duration: A) $>4$ weeks, B) $2-4$ weeks, C) $<2$ weeks, D) none

Number of persons living in same apartment with subjects: A) $<5$, B) $5-8$, C) $>8$

Number of dependants: A) $<5$, B) $5-9$, C) $>9$

Engaged in Social activity: 1) yes and 2) none

Siesta: 1) some siesta and 2) none

Midnight GSM calls: 1) yes and 2) none

Keeping GSM phones on at night during sleep: 1) yes and 2) no

Evening rest: 1) yes and 2) none

Akanwu use: 1) yes and 2) no

Complexion: 1) fair and 2) black

Family history of hypertension: 1) yes and 2) no

Time spent at work daily::A $<8$ hours, B $8-10$ hours, $\mathrm{C}>10$ hours

The influence of the variables on hypertension were compared between the groups for each variable.

The potential predictors of hypertension evaluated were family history of hypertension, diabetes mellitus, cigarette smoking, tobacco snuff use, educational status, alcohol use, marital status, eating at home, meat consumption, night-time sleep duration, keeping night vigil, prior knowledge of hypertension status, economic status, days spent on business in a week, days spent on weekend, annual leave duration, number of persons living in same apartment, number of dependents, social activities, siesta, keeping GSM phones on during night sleep, making midnight GSM phone calls, finding time to rest in the evening, using Akanwu, complexion, length of time spent at work daily, thickened arterial wall and BMI.

\section{Data Analyses}

The data were analyzed using the Statistical Package for Social Sciences (SSPS Inc, Chicago, IL) version 17.0 statistical software. For continuous variables, mean values and standard deviations were calculated and the means compared using ANOVA or two sample t-test. Categorical variables were compared using the nonparametric tests Chi-square. The distribution and characterization of variables with hypertension were analyzed using cross tabulation. Correlation statistics were used to determine the association between hypertension and variables, while multivariate linear regression was used to determine the strength of the variables to predict hypertension. All tests were two-tailed with $\mathrm{P}<.05$ taken as statistically significant.

\section{Definition of terms:}

Hypertension: SBP $\geq 140 \mathrm{mmHg}$ and or $\mathrm{DBP} \geq 90 \mathrm{mmHg}$ [19]

Mild hypertension: SBP 140-159 mmHg and/or DBP 90$99 \mathrm{mmHg}$

Moderate hypertension: SBP 160-179 mmHg and/or DBP 100-109 mmHg;

Severe hypertension: $\mathrm{SBP} \geq 180 \mathrm{mmHg}$ and/or $\mathrm{DBP} \geq$ $110 \mathrm{mmHg}$.

Body mass index: [20]

Underweight: BMI $<18,5 \mathrm{~kg} / \mathrm{m}^{2}$

Normal body weight: BMI $18.5-24.9 \mathrm{~kg} / \mathrm{m}^{2}$

Overweight: BMI $25.0-29.9 \mathrm{~kg} / \mathrm{m}^{2}$

Mild obesity: BMI $30.0-34.9 \mathrm{~kg} / \mathrm{m}^{2}$

Moderate obesity: BMI $35.0-39.0 \mathrm{~kg} / \mathrm{m}^{2}$

Severe obesity: BMI $\geq 40.0 \mathrm{~kg} / \mathrm{m}^{2}$

Obesity: BMI $\geq 30.0 \mathrm{~kg} / \mathrm{m}^{2}$ In this study Obesity was defined as $B M I \geq 30.0 \mathrm{~kg} / \mathrm{m}^{2}$ 
The subjects who were found to have hypertension were counselled and advised to see clinicians in the hospitals.

\section{Results}

The study subjects were 294. Males made up 27.9\% and females $72.1 \%$. The mean age of the study subjects was $43.13 \pm 15.38$ years, and range 70 years. Their mean BMI was $28.1 \pm 6.0 \mathrm{~kg} / \mathrm{m} 2)$, SBP $129.3 \pm 23.7 \mathrm{mmHg}$ and DBP $82.6 \pm 14.7 \mathrm{mmHg}$ (Table 1$)$. Out of the 294 subjects studied, $122(41.5 \%)$ have hypertension (SBP $\geq 140$ and/or DBP $\geq 90 \mathrm{mmHg})$. Of these, $38(31.1 \%)$ were males whereas 84(68.9\%) were females. Among those that have hypertension, 56(45.9\%) were aware of their status, whereas 66(54.1\%) were unaware they were hypertensive prior to the study. Majority (98.6\%) of the study subjects were Igbos, whereas only $1.4 \%$ were Hausas.

There was no significant association between gender and hypertension, $\mathrm{df}=1, \mathrm{p}=0.294$ (Table 2).

The association between hypertension and BMI was significant, $d f=3, p=0.018$. Out of 122 subjects that have hypertension, $2(1.6 \%)$ have BMI $<18.5 \mathrm{~kg} / \mathrm{m} 2$, 26(21.3\%) have BMI 18.5 - 24.9kg/m2, 42(34.2\%) have BMI 25.0 $29.91 \mathrm{~g} / \mathrm{m} 2$ wheras $52(42.6 \%)$ have BMI $\geq 30.0 \mathrm{~kg} / \mathrm{m} 2$. This showed that the prevalence of hypertension increased as BMI increased (Figure 1, Table 2).

There was significant association between hypertension and cigarette smoking, $\mathrm{df}=1, \mathrm{p}=0.015$. Sixteen subjects were smokers. Out of this number, 2(12.5\%) have hypertension whereas $14(87.5 \%)$ did not. Similarly, out of 275 subjects who were not smokers, 120(43.2\%) have hypertension whereas 158(56.8\%) did not. This demonstrated that hypertension was higher among non-smokers than smokers (Table 2).
Educational status has a significant association with hypertension, $\mathrm{df}=3, \mathrm{p}<0.001$. The prevalence of hypertension was highest among those with primary education (40.0\%), lowest among those with no education (11.4\%), followed by those with secondary education $24.6 \%$ ) and those with tertiary education 23.0\%) (Table 2).

There was significant association between thickened arterial wall and hypertension, $\mathrm{df}=1, \mathrm{p}<0.001$. Out of 80 subjects who have thickened arterial wall, 58(72.5\%) have hypertension whereas 22(27.5\%) did not. In contrast, out of 214 subjects that have no thickened arterial wall, 64(29.9\%) have hypertension while 150(70.1\%) did not. This showed that the prevalence of hypertension was significantly higher in subjects that have thickened arteria wall than those with normal arterial wall (Figure 2, Table 2).

Table 1. Characteristics of study subjects $n=294$

\begin{tabular}{|l|c|}
\hline Variables & Study Subjects \\
\hline Age (years) $(\mathrm{M} \pm \mathrm{SD})$ & $43.13 \pm 15.38$ \\
\hline Age Distribution & $68(23.1 \%)$ \\
\hline $20-29 y e a r s$ & $72(24.5 \%)$ \\
\hline $30-39 y e a r s$ & $44(15.0 \%)$ \\
\hline $40-49 y e a r s$ & $62(21.1 \%)$ \\
\hline $50-59 y e a r s$ & $34(11.6 \%)$ \\
\hline $60-69 y e a r s$ & $12(4.1)$ \\
\hline $70-79 y e a r s$ & $-0-$ \\
\hline 80 -89years & $2(7.0 \%)$ \\
\hline 90 -99years & $28.1 \pm 6.0$ \\
\hline BMI (kg/m $\left.{ }^{2}\right)(M \pm \mathrm{SD})$ & $129.3 \pm 23.7$ \\
\hline Systolic blood pressure $(\mathrm{mmHg})(\mathrm{M} \pm \mathrm{SD})$ & $82.6 \pm 14.7$ \\
\hline Diastolic blood pressure $(\mathrm{mmHg})(\mathrm{M} \pm \mathrm{SD})$ & \\
\hline SD=standard deviation, $\mathrm{M}=\mathrm{mean}, \mathrm{BMI}=$ body mass index \\
\hline
\end{tabular}

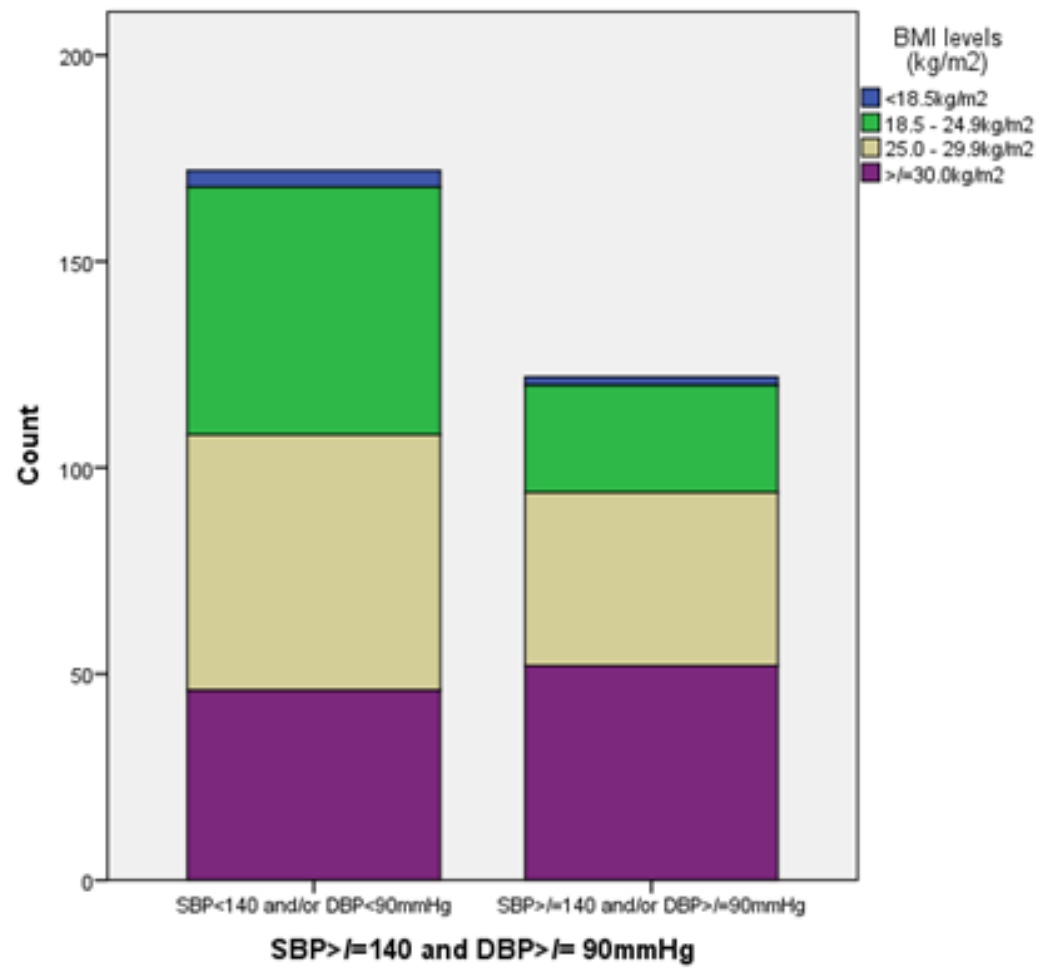

Figure 1. Association between hypertension and BMI 
Table 2. Distribution and characterization of variables among subjects with and those without hypertension in a market population

\begin{tabular}{|c|c|c|c|c|c|c|}
\hline VARIABLES & $\begin{array}{c}\text { HYPERTENSION } \\
\text { Absent } \\
(\mathbf{n} / \%) \mathbf{N}=110\end{array}$ & $\begin{array}{c}\text { HYPERTENSION } \\
\text { Present } \\
(\mathbf{n} / \%) \mathrm{N}=\mathbf{2 0}\end{array}$ & $\begin{array}{l}\text { Chi } \\
\text { Square }\end{array}$ & df & LHR & $P$ value \\
\hline Gender Male & $44(53.7 \%)$ & $38(46.3 \%)$ & 1.099 & 1 & 0.296 & 0.294 \\
\hline Female & $128(60.4 \%)$ & $84(39.5 \%)$ & & & & \\
\hline $\mathrm{BMI}<18.5$ & $4(2.3 \%)$ & $2(1.6 \%)$ & 10.111 & 3 & 0.017 & 0.018 \\
\hline $18.5-24.9$ & $60(34.9 \%)$ & $26(21.3 \%)$ & & & & \\
\hline $25.0-29.9$ & $62(36.0 \%)$ & $42(34.4 \%)$ & & & & \\
\hline$\geq 30$ & $46(26.7 \%)$ & $52(42.6 \%)$ & & & & \\
\hline Smoking Yes & $14(87.5 \%)$ & $2(12.5 \%)$ & 5.860 & 1 & 0.031 & 0.015 \\
\hline No & $158(56.8 \%)$ & $120(45.2 \%)$ & & & & \\
\hline Educational status None & $20(58.8 \%)$ & $14(41.2 \%)$ & 27.527 & 3 & $<0.001$ & $<0.001$ \\
\hline Primary & $26(34.2 \%)$ & $50(65.8 \%)$ & & & & \\
\hline Secondary & $78(72.2 \%)$ & $30(27.8 \%)$ & & & & \\
\hline Tertiary & $48(63.2 \%)$ & $28(36.8 \% 0$ & & & & \\
\hline Arterial wall thickened & $22(27.5 \%)$ & $58(72.5 \%)$ & 43.516 & 1 & $<0.001$ & $<0.001$ \\
\hline Not thickened & $150(70.1 \%)$ & $64(29.9 \%)$ & & & & \\
\hline Marital status single3 & $32(18.6 \%)$ & $10(8.2 \%)$ & 18.248 & 3 & $<0.001$ & $<0.001$ \\
\hline Married & $122(70.8 \%)$ & $82(67.2 \%)$ & & & & \\
\hline Divorced & $0(0.0 \%)$ & $6(4.9 \%)$ & & & & \\
\hline Widowed & $18(10.5 \%)$ & $24(19.7 \%)$ & & & & \\
\hline DM status Known & $6(21.4 \% 0$ & $22(78.6 \%)$ & 17.522 & 1 & $<0.001$ & $<0.001$ \\
\hline Not known & 166(62.4\%) & $100(37.6 \%)$ & & & & \\
\hline No in apt $<5$ & $68(51.5 \%)$ & $64(48.5 \%)$ & 6.713 & 2 & 0.034 & 0.035 \\
\hline $5-8$ & $94(66.2 \%)$ & $48(33.2 \%)$ & & & & \\
\hline$>8$ & $10(50.0 \%)$ & $10(50.0 \%)$ & & & & \\
\hline Dependants $<5$ & 118(68.6\%) & $66(54.1 \%)$ & 6.789 & 2 & 0.034 & 0.034 \\
\hline $5-9$ & $50(29.1 \%)$ & $50(41.0 \%)$ & & & & \\
\hline$>9$ & $4(2.3 \%)$ & $6(4.9 \%)$ & & & & \\
\hline Complexion Fair & $34(38.6 \%)$ & $54(61.4 \%)$ & 20.419 & 1 & $<0.001$ & $<0.001$ \\
\hline Black & 138(67.0\%) & $68(33.0 \%)$ & & & & \\
\hline Fam Hx Htn Present & $34(39.5 \%)$ & $52(60.5 \%)$ & 18.016 & 1 & $<0.001$ & $<0.001$ \\
\hline Absent & $138(66.3 \%)$ & $70(33.7 \%)$ & & & & \\
\hline
\end{tabular}

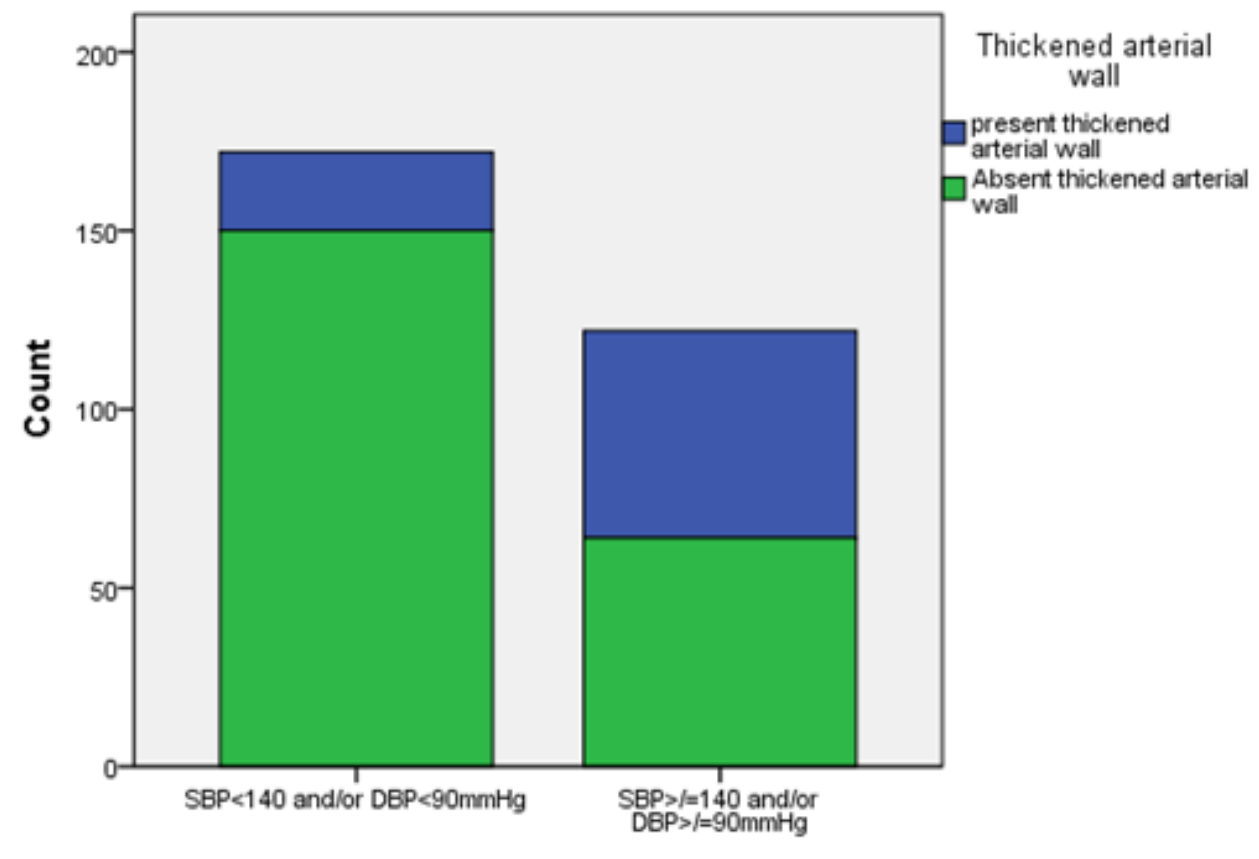

$S B P>l=140$ and $D B P>l=90 \mathrm{mmHg}$

Figure 2. Association between hypertension and age 
The association between hypertension and marital status was significant, $d f=3, p<0.001$. The prevalence of hypertension was highest among married subjects (67.2\%), followed by widowed subjects (19.7\%), single subjects (8.2\%) and divorced subjects (4.9\%) (Table 2).

No significant association was observed between hypertension and eating at home/outside the home $(\mathrm{df}=2$, $\mathrm{p}=0.139)$, meat consumption $(\mathrm{df}=1, \mathrm{p}=0.081)$, duration of night-time sleep $(\mathrm{df}=2, \mathrm{p}=0.661)$, night vigil $\mathrm{df}=1$, $\mathrm{p}=0.954$ ) (Table 2).

There was significant association between hypertension and diabetes mellitus status of the subjects, $\mathrm{df}=1, \mathrm{p}<0.001$. The number of subjects whose diabetes mellitus status was known prior to the screening was 28. Out of this number, 22(78.6\%) have hypertension whereas 6(21.4\%) did not. In contrast, 266 subjects did not know their diabetes mellitus status. Out of this number, $100(37.6 \%)$ have hypertension whereas 166(62.4\%) did not> This showed that the prevalence of hypertension was significantly higher in subjects previously known to have diabetes mellitus than those whose diabetes mellitus status was not known prior to the screening (Table 2).

The association between hypertension and economic status was significant, $\lambda^{2}=18.994, \mathrm{df}=5, \mathrm{LHR}=0.001$, $\mathrm{p}=0.002$. Out of 122 that have hypertension, the prevalence of hypertension was highest among minor retailers (60.7\%), followed by artisans (11.5\%), government workers (6.6\%), and major retailers (4.9\%).

No significant association was observed between hypertension and number of days spent in business $\left(\lambda^{2}=6.875, \mathrm{df}=3, \mathrm{LHR}=0.071, \mathrm{p}=0.075\right)$, number of days spent on weekend $\left(\lambda^{2}=6.147, \mathrm{df}=3, \mathrm{LHR}=0.095, \mathrm{p}=0.105\right)$, as well as annual leave duration $\left(\lambda^{2}=5.801, \mathrm{df}=3\right.$, LHR=0.047, $\mathrm{p}=0.122$ ).

Hypertension has significant association with the number of persons living in same apartment, $\mathrm{df}=2$, $\mathrm{p}=0.035$. Out of 122 who have hypertension, 64(52.4\%) lived with $<5$ persons, 48(39.3\%) with $6-8$ persons, whereas $10(8.2 \%)$ lived with $>8$ persons. The prevalence of hypertension was highest among those living with $<5$ persons and lowest among those living with $>8$ persons (Table 2).

There was significant association between hypertension and number of dependants, $\mathrm{df}=2, \mathrm{p}=0.034$. Out of the 122 subjects that have hypertension, 66(54.1\%) have $<5$ dependants, $50(41.0 \%)$ have $5-9$ dependants whereas $6(4.9 \%)$ have $>9$ dependants. This showed that the prevalence of hypertension decreased as the number of dependants increased (Table 2).

No significant association was observed between hypertension and social activities $\left(\lambda^{2}=0.251, \mathrm{df}=1\right.$, LHR=0.122, $\mathrm{p}=0.169)$, keeping GSM phone on at night $\left(\lambda^{2}=0.084, \mathrm{df}=1, \mathrm{LHR}=0.771, \mathrm{p}=0.771\right)$, making midnight GSM calls $\left(\lambda^{2}=4.353, \quad \mathrm{df}=2, \quad \mathrm{LHR}=0.081, \mathrm{p}=0.113\right)$, evening rest $\left(\lambda^{2}=1.748, \mathrm{df}=2, \mathrm{LHR}=0.290, \mathrm{p}=0.417\right)$, Akanwu use $\left(\lambda^{2}=0.686, \mathrm{df}=4, \mathrm{LHR}=0.479, \mathrm{p}=0.408\right)$, as well as time spent at work daily $\left(\lambda^{2}=3.961, \mathrm{df}=3\right.$, LHR=0.198, $\mathrm{p}=0.266$ ).

There was significant association between hypertension and complexion, $\mathrm{df}=1, \mathrm{p}<0.001$. Out of 88 subjects who were fair in complexion, 54(61.4\%) have hypertension. In contrast, out of 206 subjects who were black in complexion, 68(33.0\%) have hypertension. This showed that fair skin subjects have significantly higher prevalence of hypertension than black skin subjects (Table 2).

Family history of hypertension was significantly associated with hypertension, $d f=1, p<0.001$. Eighty-eight subjects responded "yes" to family history of hypertension. Out of this number, 52(60.5\%) have hypertension whereas 54(39.5\%) did not. In contrast, out of 208 subjects who responded "no" to family history of hypertension, 70(33.7\%) have hypertension whereas 138(66.3\%) did not (Table 2).

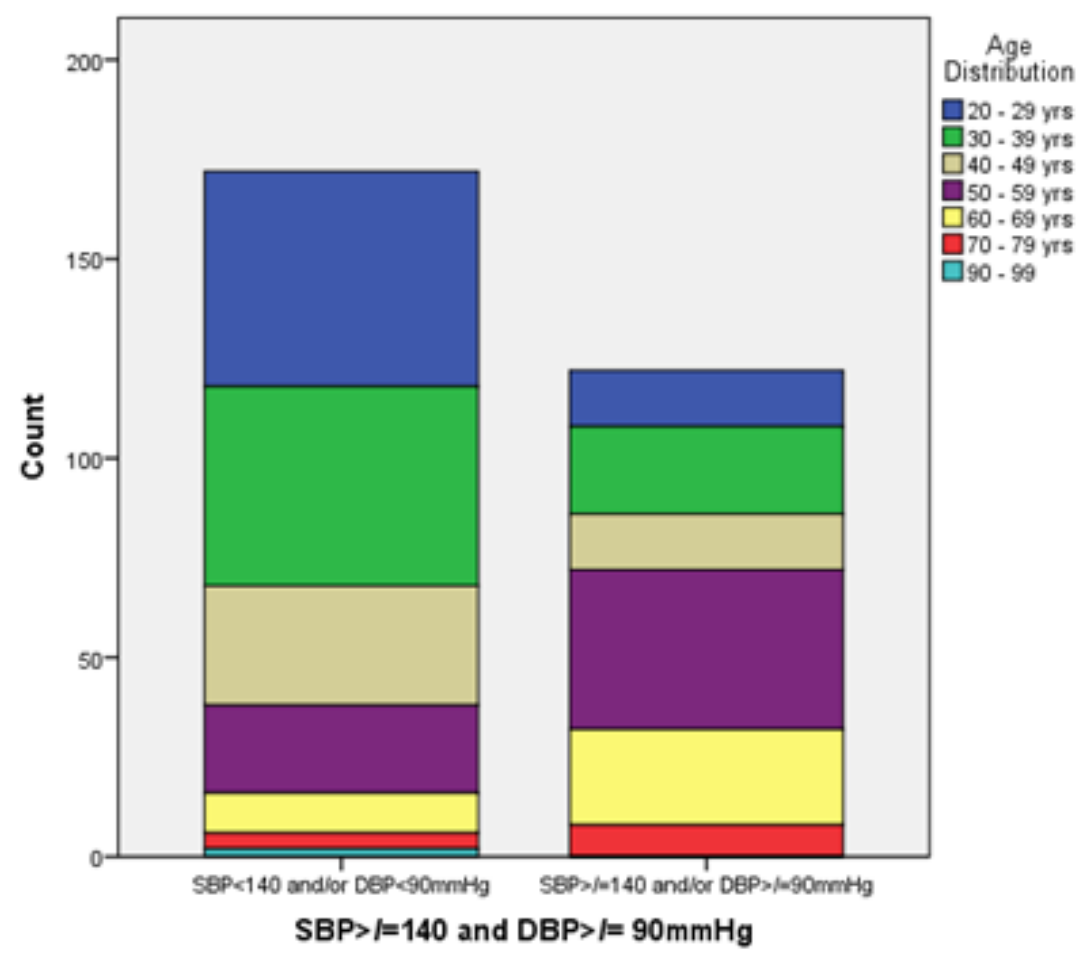

Figure 3. Association between hypertension and thickened arterial wall 
Table 3. Distribution and characterization of Age distribution among subjects with and those without hypertension in a market population

\begin{tabular}{|c|c|c|c|c|c|c|}
\hline Age Distribution & $\begin{array}{c}\text { HYPERTENSION } \\
\text { Absent } \\
(\mathbf{n} / \%) \mathrm{N}=110 \\
\end{array}$ & $\begin{array}{c}\text { HYPERTENSION } \\
\text { Present } \\
(\mathbf{n} / \%) \mathrm{N}=20\end{array}$ & $\begin{array}{l}\text { Chi } \\
\text { Square }\end{array}$ & df & LHR & $P$ value \\
\hline 20 - 29 years & $54(79.4 \%)$ & $14(20.6 \%)$ & 47.429 & 6 & $<0.001$ & $<0.001$ \\
\hline $30-39$ years & $50(69.4 \%)$ & $22(30.6 \%)$ & & & & \\
\hline 40 - 49years & $30(68.2 \%)$ & $14(31.8 \%)$ & & & & \\
\hline 50 - 59years & $22(35.5 \%)$ & $40(64.5 \%)$ & & & & \\
\hline 60 - 69years & 10(29.4\%) & $24(70.6 \%)$ & & & & \\
\hline 70 - 79years & 4(33.3\%) & $8(66.7 \%)$ & & & & \\
\hline 80 - 89years & $\mathrm{xxxx}$ & Xxxx & & & & \\
\hline$>90 \mathrm{yrs}$ & $2(100 \%)$ & $0(0,0 \%)$ & & & & \\
\hline
\end{tabular}

Table 4. Correlation of Hypertension with selected variables in study subjects $(n=122)$

\begin{tabular}{|c|c|c|}
\hline Variables & Correlation coefficient(r) & $P$ value \\
\hline Age & 0.296 & 0.001 \\
\hline Body mass index & -0.093 & 0.310 \\
\hline Night-time sleep & 0.278 & 0.002 \\
\hline Night-time vigil & 0.174 & 0.056 \\
\hline Economic status & -0.132 & 0.082 \\
\hline Days spent in business per week & -0.129 & 0.156 \\
\hline Days spent on weekend & 0.052 & 0.568 \\
\hline Annual leave & -0.158 & 0.082 \\
\hline Number of persons living in apartment & 0.103 & 0.258 \\
\hline Dependants & 0.013 & 0.885 \\
\hline Social activities & -0.025 & 0.781 \\
\hline Siesta & -0.044 & 0.629 \\
\hline GSM keeping open at night & 0.032 & 0.729 \\
\hline Akanwu use & 0.089 & 0.518 \\
\hline Complexion & 0.221 & 0.015 \\
\hline Family history of hypertension & -0.009 & 0.926 \\
\hline Time spent at work daily & -0.184 & 0.043 \\
\hline Educational status & -0.163 & 0.004 \\
\hline Thickemed arterial wall & -0.476 & $<0.001$ \\
\hline Marital status & 0.231 & $<0.001$ \\
\hline Eats at home & 0.140 & 0.016 \\
\hline
\end{tabular}

Table 5. Multivariate linear regression of variables with Hypertension in study subjects ( $n=122)$

\begin{tabular}{|l|c|c|c|c|}
\hline Variables & Beta & T & P value & 95\% CI \\
\hline Age & 0,026 & 0.240 & 0.811 & $0.253-0.322$ \\
\hline Night-time sleep duration & 0.133 & 1.575 & 0.118 & $-1.059-9.264$ \\
\hline Tobacco snuff use & -0.288 & -3.090 & 0.003 & $-32.491--7.104$ \\
\hline Complexion & 0.029 & 0.319 & 0.752 & $-5.805-8.017$ \\
\hline Time spent at work daily & -0.107 & -1.204 & 0.231 & $-6.909-1.687$ \\
\hline Educational status & 0.059 & 0.519 & 0.605 & $-3.214-5.543$ \\
\hline Thickened arterial wall & -0.306 & -2.892 & 0.005 & $-19.490-13.643$ \\
\hline Marital status & 0.160 & 1.508 & 0.134 & $-1.065-7.852$ \\
\hline Eats at home & 0.048 & 0.542 & 0.689 & $-5.406-9.477$ \\
\hline CI=Confidence Interval. & & & \\
\hline
\end{tabular}


Age was significantly associated with hypertension, $\mathrm{df}=6, \mathrm{p}<0.001$. The prevalence of hypertension was observed to increase with age, from $20.6 \%$ in the $20-29$ years age group to $70.6 \%$ in the 60 - 69 years age group (Figure 3, Table 3).

There was significant correlation between hypertension and age $(\mathrm{p}=0.001)$, night-time sleep duration $(\mathrm{p}=0.002)$, tobacco use $(\mathrm{p}<0.001)$, complexion $(\mathrm{p}=0.015)$, time spent at work daily $(\mathrm{p}=0.043)$, educational status (0.007), thickened arterial wall $(\mathrm{p}<0.001)$ marital status $(p=<0.001)$, as well as eating at home $(p=0.016)$ (Table 4$)$.

Multivariate linear regression analysis showed that only tobacco snuff use $(\mathrm{p}=0.003)$ and thickened arterial wall $(p=0.005)$ predicted hypertension (Table 5).

\section{Discussion}

This study showed that the prevalence of hypertension was $41.5 \%$ overall, $31.1 \%$ in males and $68.9 \%$ in females. This was similar to that documented by Ulasi et al in Enugu, Nigeria, in 2011. [10] Although both studies were conducted in a market population the prevalence was not influenced by the differences in study population size and location. Striking, our study subjects, like theirs, were dominantly Igbos. Furthermore, the prevalence of hypertension obtained in this study was higher than the 23.2\% reported in another study in Southeast Nigeria in 2015. [15] This observed difference might be explained, in part, by the difference in the demography of the study subjects. Their study subjects were rural dwellers whereas ours were urban dwellers. Hypertension has been documented to be higher in urban population than in rural dwellers. [7,8,9]

High unawareness of hypertension in this study (54.1\%) was nonetheless, lower than that observed in the Ulasi et al study previously mentioned. [10] The time lapse between their study (2011) and ours 2016) might account for this difference. A measure of awareness, over time, might have stimulated a positive change arising from awareness creation and mass education information through the media and healthcare providers on preventives measures against hypertension and its associated factors, a wave that might have spread to our domain.

In this study we observed that hypertension was more prevalent in females (68.9\%) than in males (31.1\%). This differed from that in two studies, which noted that more males than females were hypertensive. [10] This might have stemmed from the fact that our study subjects were dominantly females.

In this study, significant association was observed between hypertension and BMI.

It further showed that the prevalence of hypertension increased as BMI increased. Hypertension was more prevalent in obese subjects than those with normal weight or underweight. This finding agrees with observations documented in some studies. [10,21] Obesity is known to predispose to hypertension. [22]

This study observed a significant association between hypertension and cigarette smoking. The prevalence of hypertension was higher in non-smokers than smokers. This is at variance with a study that has documented a direct association between hypertension and cigarette use. [23]
In this study, it was observed that the association between hypertension and alcohol use was not significant. Alcohol is known to influence dyslipidemia and vascular changes which would cause peripheral resistance and predispose to hypertension. [24] However, our finding in this study contrasted with this assertion.

It was noted in this study that educational status has a significant association with hypertension. The prevalence of hypertension was highest among those with primary education (40.0\%), lowest among those with no education (11.4\%), followed by those with secondary education $24.6 \%$ ) and those with tertiary education (23.0\%). Perhaps, those with low educational status might also have poor access to, and ignorance of, information targeted at preventive measures against hypertension. [25]

Our study showed a significant association between thickened arterial wall and hypertension. It demonstrated that the prevalence of hypertension was significantly higher in subjects that have thickened arterial wall than those whose arterial wall was normal. Arterial wall thickening will reduce vascular compliance and increase peripheral resistance, which in turn will induce the generation of hypertension. [26]

It was observed in this study that the association between hypertension and marital status was significant. The prevalence of hypertension was highest in married subjects (67.2\%), followed by widowed subjects (19.7\%), single subjects (8.2\%) and divorced subjects (4.9\%). Marriage should be a zone of comfort and should provide a soothing haven to bolster down blood pressure. Our finding here, showed the opposite. A study however, showed a contrary observation, associating hypertension with divorce. [27]

In this study, no significant association was observed between hypertension and eating at home/outside the home, meat consumption, duration of night-time sleep, night vigil. Eating at home, in our traditional setting, would usually provide succor that would nourish family unity and love, and expectedly would help curb the prevalence of hypertension. Meat consumption, perhaps, over time might influence renal damage and trigger hypertension. Both were found not to have an influence on hypertension. Duration of night-time sleep, if grossly inadequate, may influence the onset of hypertension. One Korean study found a high prevalence of hypertension among those engaged in nighttime duties. [28] However, we did not evaluate the effect of regular night duties on hypertension. In addition, the population we studied was very small compared to theirs.

It was demonstrated in this study that the association between hypertension and diabetes mellitus status of the subjects was significant. It was observed that the prevalence of hypertension was significantly higher in subjects previously known to have diabetes mellitus than those whose diabetes mellitus status was not known prior to the screening. The natural history of diabetes mellitus is known to be associated with hypertension as it progresses. [29] This tends to suggest that the hypertensive diabetic subjects among our study population might have progressed to the hypertensive phase at the time of this study.

This study showed that the association between hypertension and economic status was significant. It 
further showed that the prevalence of hypertension was highest in minor retailers (60.7\%), followed by artisans (11.5\%), government workers (6.6\%), and major retailers (4.9\%). Though markets in Nigeria have heterogeneous populations, with bee hives of commercial activities, poor artisans and minor retailers among them still showed dominance of hypertension, as was also documented in a study. [30]

In this study, no significant association was observed between hypertension and number of days spent in business, number of days spent on weekend, as well as annual leave. There was dearth of studies on the association between hypertension and these variables. Spending much time in business, little or no rest on weekends and virtually no annual leave would likely produce stress that may impact negatively on generation of hypertension. [31] Nevertheless, these were not observed in this study.

This study showed that hypertension has significant association with the number of persons living in the same apartment. It further observed that the prevalence of Hypertension was highest in those living with $<5$ persons and lowest in those living with $>8$ persons. It was also noted in this study that the association between hypertension and number of dependants was significant. The prevalence of hypertension decreased as the number of dependants increased. Living in an apartment with many persons might provide an atmosphere of African sharing and extended family tenets which tends to promote happiness and alleviation of social burden. This, perhaps might account for the observed results in this study.

Our study did not show significant association between hypertension and social activities, keeping GSM phone on at night, making midnight GSM calls, evening rest, as well as time spent at work. These activities usually infringe on the quality of night-time sleep. However, they showed no significant influence on hypertension in the subjects studied.

Akanwu, a product that contains substantial amount of potash, is used by our people in enhancing the cooking of bread-fruit, bitterleaf soup, stock fish, etc. Its use was not observed to have a significant association with hypertension. One study has reported an association between hypertension and Akanwu use, contrary to our observation. [32]

In this study, there was significant association between hypertension and complexion. It demonstrated that fair skin subjects have significantly higher prevalence of hypertension than black skin subjects. There was a drought of studies on the association between hypertension and complexion.

It was observed in this study that family history of hypertension was significantly associated with hypertension. This is in conformity with global observation that hypertension occurs commonly in those with a family history of hypertension. [33]

This study showed that age was significantly associated with hypertension. The prevalence of hypertension was observed to increase with age, from $20.6 \%$ in the $20-29$ years age group to $70.6 \%$ in the $60-69$ years age group. This observation reflected the global trend. [10,34]

As demonstrated in this study, only tobacco snuff use and thickened arterial wall were predictors of hypertension. From literature search, there was a paucity of studies on the association between hypertension and tobacco snuff. Nevertheless, tobacco snuff contains nicotine and potash both of which have been reported to influence blood pressure. [32,35] Arterial wall thickening, as in this study, has been documented as a risk factor of cardiovascular disease. [26]

\section{Conclusion}

The prevalence of hypertension (41.5\%) and unawareness of hypertension $(54.1 \%)$ were high in this study. Obesity, cardiovascular risks, family size, low income and low educational status were common among hypertensive subjects. There is a need for government and healthcare providers to screen market workers, on large scales, for hypertension, create awareness strategies, educate them, and institute intervention measures to whittle down these factors which influence hypertension

\section{Limitations}

The study population was not structured. It was a crosssectional study, in which many eligible subjects were missed out. The study population was also small. The blood pressure was taken in one sitting only. This might have affected the overall prevalence in this study.

\section{What is Already Known about This Topic}

A The prevalence of hypertension is high in Nigeria but isolated market workers' populations are not routinely screened for hypertension.

B Market workers live a sedentary life style and consume high salt diets which predispose to hypertension.

$\mathrm{C}$ The factors which influence hypertension in market workers have not been completely identified.

\section{What This Study Adds}

A Hypertension is prevalent in market workers in Awka, Southest Nigeria.

B About half of the market workers were unaware of their condition.

C Obesity, cardiovascular risks, family size, low income and low educational status were common among the market workers who were hypertensive.

\section{Competing Interests}

The authors declare no competing interest.

\section{Authors' Contributions}

The authors have read and agreed to the final version of this manuscript. 


\section{References}

[1] Kearney PM, Whelton M, Reynolds K, Whelton PK, He J. Worldwide prevalence of hypertension: a systematic review. J Hyperten. 2004; 22(1):11-19.

[2] Kearney PM, Whelton M, Reynolds K, Muntner P, Whelton PK, He J. Global burden of hypertension: analysis of worldwide data. Lancet. 2005; 365(9455): 217-223.

[3] World Health Organization. A global brief on hypertension: silent killer, global public health crises (World Health Day 2013). Geneva: WHO 2013; Available: http://apps.who.int/iris/bitstream/10665/79059/1/WHO_DCO_W HD_2013.2_eng.pdf Accessed 2015 Feb 11.

[4] Wang X, Bots ML,; Yang F, Hoes AW, Vaartjes I. Prevalence of hypertension in China: a systematic review and meta-regression analysis of trends and regional differences. J Hypertens. 2014 32(10): 1919-1927.

[5] Nwankwo T,, M.S.; Sung Yoon SS,, Burt V, Gu O.. Hypertension Among Adults in the United States: National Health and Nutrition Examination Survey, 2011-2012. National Center for Health Statistics. NCHS Data Brief No. 133, October 2013. Available at https://www.cdc.gov/nchs/products/databriefs/db133.htm Accessed on 09.01/2017.

[6] Joshi MD, Email author, Ayah R, Njau EK,, Wanjiru R,, Kayima JK,, Njeru EK, Mutai. Prevalence of hypertension and associated cardiovascular risk factors in an urban slum in Nairobi, Kenya: A population-based survey. BMC Public Health 2014; 14:1177.

[7] Kingue S, Ngoe CN, Menanga AP, Jingi AM, Noubiap JJ, Fesuh B, Nouedoui C, Andze G, Muna WF. Prevalence and Risk Factors of Hypertension in Urban Areas of Cameroon: A Nationwide Population-Based Cross-Sectional Study. J Clin Hypertens (Greenwich). 2015 Oct; 17(10):819-24.

[8] Addo J, Agyemang C, Smeeth L, de-Graft Aikins A, Edusei AK, Ogedegbe O. A review of population-based studies on hypertension in Ghana. Ghana Med J. 2012 Jun; 46(2 Suppl):4-11.

[9] Adeloye D, Basquill C, Aderemi AV, Thompson JY, Obi FA. An estimate of the prevalence of hypertension in Nigeria: a systematic review and meta-analysis. J Hypertens. 2015 Feb; 33(2):230-42.

[10] Ulasi II, Ijoma CK, Onwubere BJC, Arodiwe E, Onodugo O, Okafor C.. High Prevalence and Low Awareness of Hypertension in a Market Population in Enugu, Nigeria. Int J Hypertens. 2011; 2011: 869675.

[11] Stanley S. Franklin, Nathan D. Wong. Hypertension and Cardiovascular Disease: Contributions of the Framingham Heart Study. Global heart. March 2013; 8(1): 49-57.

[12] Centers for Disease Control and Prevention. National Center for Health Statistics. Hypertension. Available at https://www.cdc.gov/nchs/fastats/hypertension.htm Accessed on 09/01/2017.

[13] Bloom, D.E., Cafiero, E.T., Jané-Llopis, E., Abrahams-Gessel, S., Bloom, L.R., Fathima, S., Feigl, A.B., Gaziano, T., Mowafi, M., Pandya, A., Prettner, K., Rosenberg, L., Seligman, B., Stein, A.Z., \& Weinstein, C. The Global Economic Burden of Noncommunicable Diseases. Geneva: World Economic Forum. 2011. Available at www.weforum.org/EconomicsOfNCD. Accessed on 09/01/2017.

[14] Steven van de Vijver, Hilda Akinyi, Samuel Oti, Ademola Olajide, Charles Agyemang, Isabella Aboderin, Catherine Kyobutungi. Status report on hypertension in Africa - Consultative review for the 6th Session of the African Union Conference of Ministers of Health on NCD's. Pan Afr Med Jl. 2013; 16: 38.

[15] Ugwuja EI, Ezenkwa US, Nwibo AN, Ogbanshi M, Idoko O, Nnabu R. Prevalence and Determinants of Hypertension in an Agrarian Rural Community in Southeast Nigeria. Ann Med Health Sci Res. 2015 Jan-Feb; 5(1): 45-49.

[16] Rothwell PM, Howard SC, Spence JD. Relationship Between Blood Pressure and Stroke Risk in Patients With Symptomatic Carotid Occlusive Disease. Stroke. 2003; 34: 2583-2590.
[17] Anil K. Bidani, Karen A. Griffin. Pathophysiology of Hypertensive Renal Damage Implications for Therapy. Hypertension. 2004; 44: 595-601.

[18] Henderson AD, Beau B. Bruce., Nancy J. Newman, Valérie Biousse. Hypertension-related eye abnormalities and the risk of stroke. Rev Neurol Dis. 2011; 8(1-2): 1-9.

[19] Whitworth JA. World Health Organization (WHO)/International Society of Hypertension (ISH) statement on management of hypertension. Journal of Hypertension. 2003; 21(11):1983-1992.

[20] WHO (1995) Physical Status: The Use and Interpretation of Anthropometry. Technical Report Series 854, 1-1-9950. World Health Organization, Geneva.

[21] Suman Dua, Monika Bhuker, Pankhuri Sharma, Meenal Dhall, and Satwanti Kapoor. Body Mass Index Relates to Blood Pressure Among Adults. N Am J Med Sci. 2014 Feb; 6(2): 89-95.

[22] John E. Hall, Jussara M. do Carmo, Alexandre A. da Silva, Zhen Wang, Michael E. Hal. Obesity-Induced Hypertension Interaction of Neurohumoral and Renal Mechanisms. Circulation Research. 2015; 116:991-1006.

[23] Virdis A, Giannarelli C, Neves MF, Taddei S, Ghiadoni L. Cigarette smoking and hypertension. Curr Pharm Des. 2010; 16(23): 2518-25.

[24] Kazim Husain, Rais A Ansari, and Leon Ferder. Alcohol-induced hypertension: Mechanism and prevention. World J Cardiol. 2014; 6(5): 245-252.

[25] Michelle A Mendez, Richard Cooper, Rainford Wilks, Amy Luke and Terrence Forrester. Income, education, and blood pressure in adults in Jamaica, a middle-income developing country. Int. J. Epidemiol. (2003) 32 (3): 400-408.

[26] Stéphane Laurent. Arterial Wall Hypertrophy and Stiffness in Essential Hypertensive Patients. Hypertension. 1995; 26: 355-362.

[27] Daily Mail Reporter. Divorce linked to high blood pressure: Relationship break-ups could increase chances of heart attacks, strokes and kidney damage. Mail Online. Health. 19 July 2014.

[28] Sungjin Park, Juhyun Nam, Jong-Ku Lee, Sung-Soo Oh, Hee-Tae Kang and Sang-Baek KohE. Association between night work and cardiovascular diseases: analysis of the 3rd Korean working conditions survey. Annals of Occupational and Environmental Medicine. 2015; 27:15.

[29] Hamilton BP. Diabetes mellitus and hypertension. Am J Kidney Dis. 1990 Oct; 16(4 Suppl 1):20-9.

[30] Michelle A Mendez1, Richard Cooper2, Rainford Wilks3, Amy Luke2 and Terrence Forrester. Income, education, and blood pressure in adults in Jamaica, a middle-income developing country. Int. J. Epidemiol. 2003; 32 (3): 400-408.

[31] Kulkarni S1, O'Farrell I, Erasi M, Kochar MS. Stress and hypertension. WMJ. 1998 Dec; 97(11):34-8.

[32] Some Harmful Traditional Birth Practices In Northern Nigeria and Making Child Birth Safer in Nigeria. Dr. Abdullahi Dahiru. Available at http://www.gamji.com/article8000/NEWS8634.htm Accessed on 09/01/2017.

[33] Matthew F. Muldoon, Debra F. Terrell, Clareann H. Bunke, Stephen B. Manuck. Family History Studies in Hypertension Research Review of the Literature. Am J Hypertens. 1993; 6 (1): 76-88.

[34] Anderson GH. Effect of Age on Hypertension: Analysis of Over 4,800 Referred Hypertensive Patients. Saudi J Kidney Dis Transpl [serial online] 1999 [cited 2017 Jan 9]; 10: 286-97.

[35] Mariann R. Piano, Neal L. Benowitz, Garret A. FitzGerald, Susan Corbridge, Janie Heath, Ellen Hahn, Terry F. Pechacek, George Howard, on behalf of the American Heart Association Council on Cardiovascular Nursing. AHA Policy Statement. Impact of Smokeless Tobacco Products on Cardiovascular Disease: Implications for Policy, Prevention, and Treatment. A Policy Statement From the American Heart Association. Circulation. 2010; 122: 1520-1544. 